\title{
Impact of mentor-mentee fit in preparing undergraduate STEM students to teach engineering technology for elementary students
}

\section{Dr. Lei Xie, TEXAS STATE UNIVERSITY}

Dr. Lei Xie is an Assistant Professor at the Department of Organization, Workforce, and Leadership Studies at Texas State University.

\section{Dr. Malini Natarajarathinam, Texas A\&M University}

Dr. Malini Natarajarathinam joined the faculty of Industrial Distribution Program at Texas A\&M University in 2007. Natarajarathinam received her Ph.D. in Supply Chain Management from The University of Alabama. She received her Bachelor of Engineering (Major: Industrial and Systems Engineering) from Anna University [Tamilnadu, India], her MS in Industrial Engineering from Auburn University, her MA in Management Science and MS in Applied Statistics from The University of Alabama. She has experience working with many industries such as automotive, chemical distribution etc. on transportation and operations management projects. She works extensively with food banks and food pantries on supply chain management and logistics focused initiatives. Her graduate and undergraduate students are integral part of her service-learning based logistics classes.

She teaches courses in strategic relationships among industrial distributors and distribution logistics. Her recent research focuses on engineering education and learning sciences with a focus on how to engage students better to prepare their minds for the future. Her other research interests include empirical studies to assess impact of good supply chain practices such as coordinated decision making in stochastic supply chains, handling supply chains during times of crisis and optimizing global supply chains on the financial health of a company. She has published her research in Journal of Business Logistics, International Journal of Physical Distribution and Logistics Management and peer-reviewed proceedings of the American Society for Engineering Education.

\section{Dr. Bugrahan Yalvac, Texas A\&M University}

Bugrahan Yalvac is an associate professor of science and engineering education in the Department of Teaching, Learning, and Culture at Texas A\&M University, College Station. He received his Ph.D. in science education at the Pennsylvania State University in 2005. Prior to his current position, he worked as a learning scientist for the VaNTH Engineering Research Center at Northwestern University for three years. Yalvac's research is in STEM education, 21st century skills, and design and evaluation of learning environments informed by the How People Learn framework. 


\title{
Impact of mentor-mentee fit in preparing undergraduate STEM students to teach engineering technology for elementary students
}

\begin{abstract}
Mentoring is being prevalently used in higher education. Traditionally, these programs are unidirectional that includes forward knowledge transfer. The internal mechanism of how to form an effective mentoring relationship between mentors and mentees is unclear. This pilot study focused on Person-Environment (P-E) fit perspective and zeroed in on how the mentormentee relationship affect mentees' self-efficacy. We conducted semi-structured interviews with three mentees to explore how P-E fit affected their self-efficacy. This qualitative study is a pilot study, future data collection and analysis will continue.
\end{abstract}

\section{Introduction}

Research has found that higher quality mentor-mentee relationships produce better outcomes [1]. Ergo, recent studies focus on discerning factors that produce higher quality mentoring relationships. In higher education, numerous scholars have focused on mentor-mentee relationship regarding the population of college engineering students. But the impact of the mentor-mentee relationship on students' self-efficacy in STEM teaching remained scarce. First of all, the interactions between STEM students and their mentors are infrequently enough, particularly the ones between racial/ethnic minorities students and their mentors [2]. Second, the culprit may be the lack of structure of how to assign different mentors to students or concreate findings of what exactly mentors do for their students can increase students' self-efficacy in teaching STEM [3].

Overall, the literature supports mentor's positive contribution to students' development. At the college level, students having a mentor is essential to their success at the college level. Mentoring is found contributive to, at least in part, leadership development, first-year college 
students' transition into a new environment, student retention and their college attitudes, and learning effectiveness in general $[4,5]$. Beyond the educational purposes, having a mentor is critical for students' personal and professional growth [6].

Traditionally, mentor-mentee relationship is unidirectional and it emphasizes on one to one skill building through active listening, positive and support interpersonal communication for both the mentor and mentee [7]. The relationship between mentor and mentee is typically hierarchical, suggesting a knowledge transfer from an experienced individual to a less experienced one. However, from the Person-Environment (P-E) fit perspective, few have recognized that the fitness between mentor and mentee at the beginning may affect mentee's self-efficacy. That is to say, the match between the mentor and mentee may be integral to the effectiveness of the mentoring program. For example, if a mentee is looking for assistance on how to communicate with other professors, a technical guru might not be the best mentor for the mentee.

We argue that in the mentor-mentee relationship, mentees are more likely to equip higher sense of self-efficacy when they have leeway to choose their mentors. P-E fit is a continuous process that both parties (i.e., mentors and mentees) compare their personalities and experiences [8]. In mentoring, for example, mentees who are specialists in computer programming but struggling with class management may find an experienced mentor, who is excellent at teaching more beneficial. However, if the reciprocal and ongoing P-E fit process in the intimate mentormentee relationship is misaligned, the mentorship outcome is most likely to be dreadful [8].

In this pilot qualitative case study, we have investigated the interactions among the mentors and the mentees who have been collaboratively working to provide in-class and on-time support to the elementary level teachers as they deliver technology infused and engineering 
based maker activities appropriate for the elementary student's levels. The mentees, who are the recruited undergraduate students at a Research I Institution at Southwest US, meet with three main mentors weekly over the semester to receive training on how to teach engineering to the elementary school students. The case under investigation is the weekly training sessions and their impact on mentees' approaches to and their self-efficacy in teaching. In this paper we posed one main research question:

- What was the impact of the person-environment (P-E) fit between mentor and mentee on mentee's self-efficacy in teaching engineering content to the elementary students?" The male mentors are one graduate student (doctorate level) and two faculty members (one in STEM, and one in Education) at the university. Their mentoring foci have diverged as some focused on teaching the technical knowledge and some have focused on teaching the pedagogical knowledge. The mentees' educational background, majors at the university, and previous teaching/tutoring experiences and interactions with elementary students also differ. It is likely that the mentees will response differently to the varying types of mentors because of their varied interests and expertise and thus their self-efficacy in teaching will also be affected by the interactions with their mentors $[9,10]$.

\section{Significance}

The main contribution of this study lies in examining the mentoring relationship from a P-E fit perspective in the context of teaching elementary students engineering technology content. We zero in on the mentor-mentee relationship from a P-E fit perspective, exploring the predictors of a successful mentoring program that increases mentees' self-efficacy in teaching.

\section{Literature review}


While the extant literature has addressed the significant outcome of mentees' selfefficacy in teaching [11-13], how the relationship between mentees and their mentors influence their self-efficacy is less researched, especially from the P-E fit perspective.

P-E fit Theory emphasizes the dyadic relationships between individuals and the environment [14]. P-E fit refers to "the compatibility between an individual and a work environment that occurs when their characteristics are well matched" [15]. In our case, the area of expertise that mentors offer constitutes part of mentees' external environment. According to the P-E fit theory, if mentees feel their needs match those that their mentors offer, they are likely to foster commitment to the content that the mentor delivers leading to better learning performance. Meta-analytic evidence from the industry demonstrated employees who perceive higher-levels of P-E fit tend to have more confidence in performing than those who feel lower-level fit [15].

\section{Methodology}

To answer our research question, in this pilot study, we interviewed 3 mentees using a semi-structured interview protocol as they had engaged in mentoring activities with all three different mentors. We used a Sony digital audio recorder to record the interview conversations and then transcribed them after gained the interviewees' permissions. The raw data was encrypted and is kept on a computer with passwords protection.

We used thematic narrative analysis to examine the personal experiences shared by each participant about their mentoring relationships and how this mentor-mentee relationship affects their self-efficacy in teaching [16]. We reviewed the transcripts line-by-line and generated three key themes from the transcripts.

The authors' philosophical position, constructivism, is in line with qualitative 
methodology [17]. We focus on the interactive mentoring relationship is built between mentees and mentors. Epistemologically, our knowledge of mentees self-efficacy should be gained from the life experience from the social context that the mentees reside in and the interactions with their mentors. Methodologically, we used semi-structured interviews as the main tools to collect participants' teaching experience regarding their interactions with elementary students about engineering technology related knowledge. Thus, this qualitative study approach and data collection methods were deemed appropriate. We took an inductive approach to formulate the themes [18], which entailed reading raw data including interview transcripts.

\section{Participants}

Table 1 lists the interviewees' demographic information. For confidentiality, we used pseudo names to protect individual participants' identities [17].

Table 1. Participants demographics

\begin{tabular}{|l|l|l|}
\hline Name & Gender & Major \\
\hline Angela & Female & Visualization \\
\hline John & Male & Chemical engineering \\
\hline Sabrina & Female & Physics \\
\hline
\end{tabular}

\section{Data collection}

All interviews were digitally recorded on a Sony digital audio recorder with the consent

of the interviewees. All interviews were conducted in a 30-day period in the winter of 2019. The data were collected using semi-structured interviews lasting an average of 41 minutes (ranging from 30 to 57 minutes). Since this is a polit study, we plan to continue collecting data from other mentees in the program. 


\section{Interview questions}

The interview protocol included 15 open-ended questions that the authors developed to capture how P-E fit affects mentees' self-efficacy in teaching STEM in elementary schools. Probing questions were also asked. The interviews began with questions pertaining to general mentoring experiences. For example, "What have you improved the most since the beginning of the mentoring program?" Questions continued by asking about the interviewee's experiences of how often they interact with their mentors. Follow-up questions were asked as probes to further

explore issues mentioned by the interviewee. For the question about from which they had learned the most, the interviewer asked, "Please describe the first few weeks of the program when you were with your mentor/s." A sample follow-up question would be related to knowledge management systems such as, "What goals did you have for your mentor?"

\section{Findings}

Based on the interview transcripts we came up with five main themes regarding how the relationship between mentors and mentees affect mentees' self-confidence in teaching elementary students about engineering technology.

\section{Identifying areas for improvement}

The program is designed to have mentees worked in pairs and taught engineering technology courses to third and fourth graders. However, most of them had not been formally trained to teach elementary students. At the beginning of the program the mentees felt overwhelmed. Mentees discovered their area for improvement in their first week of week. Angela shared that "it felt very overwhelming in the beginning just because we were still getting acquainted to the program." John also commented on his struggle at the beginning of the program. He said, "it was more uncomfortable interacting with them at the beginning and as time 
went on, we get to see each other more and they're just happy to see us coming all the time and they're ready to work." Sabrina was a more experienced teacher. She had had experience in teaching, but she lacked the knowledge of the course schedule in the beginning. She had several meetings with one of her mentors that helped her clarified many confusions. She said, "he is more managerial and he knows what's going on and he wants to improve the program."

\section{Impacted by certain mentors}

Being exposed to multiple mentors in the programs had rendered mentees opportunities to learn from the mentors they felt they could learn the most from. Sabrina was a confident experienced mentee who had experiences in teaching. She expressed that she had learned the most from one specific mentor as she told us that "He's taught me to always be looking into things that you're doing in more depth than what you think you should." On the other hand, because John was not an experienced teacher, he had improved the most on teaching STEM related content to children. John shared with the interviewer that "he's always calling us on every little detail about what happened, which is good. I like talking about it. So, in a one on one situation we are in a group situation and he was just targeted at you one on one."

\section{Teaching with a focus}

Andrea mentioned the importance of having an ultimate mission when she taught elementary students. She said the purpose of teaching them STEM related courses was not just to impart the knowledge but to be a role model and set examples for those elementary students. In her case, she had aligned her teaching style with one of the mentors. That mentor had emphasized the importance to be a good role model for the students at day one, even Andrea learned how to be a good instructor by having weekly discussions with peers and learning class schedules from other mentors, she shared that it was when she genuinely concerned the growth 
of students, she felt more confident to talk with students. She said, "it is all about encouraging these kids trying. To be a role model that maybe they haven't had." Andrea mentioned how that mentor shared to every mentee at the beginning of the mentoring program, "[you are encouraged to tell students that] you are just a 10-year older version of the elementary kids.”

Other mentees mentioned their skills in communication has been improved the most. Sabrina commented on her relationship progression with the elementary students: "I notice who are quiet, and draw them out and let them speak because the bottom line is to let them learn. If they don't participate, they won't learn. So, I need to be confident and have the power to control this class." She had learned the most from another mentor. She said, "I get talked over in the meetings but he's really good at managing the conversations, and then I can share my questions from my teaching, and he always answered them patiently."

\section{Discussion}

The benefits of mentoring programs have been well documented in an academic setting, particularly for students pursuing undergraduate STEM degrees [19]. We evaluated the mentor-mentee relationship by exploring one important outcome of mentees in terms of their self-efficacy in teaching STEM to elementary students. From our preliminary data analysis, higher P-E fit produced self-efficacy in teaching elementary students.

The findings shed light on the importance of early needs diagnosis the areas mentees to be improved on. With identified areas for improvement in mind helped mentees find targeted mentors. Thus, gradually, the mentees trust more the mentors they had learned the most from. Our findings corroborated the previous findings in STEM education mentoring. To build an effective mentoring relationship trust is key. This trust is formed by mentees put faith in their mentor who may fit their best interests and they have confidence to communicate with. The more they can relate to the mentor, the better mentoring experience may be generated [20]. 
How to mentor STEM graduates to teach k-12 children and most importantly to raise elementary students' interests in STEM is critical. We found that in the mentoring program, mentors used a wide array of interactive support strategies, such as peer support program, group dialogue, and inquiry and feedback, that diagnose mentees' teaching and keep reminding the primary objective of the programsetting examples for elementary students for the future. Undergraduate mentees learned teaching techniques through intentionally designed with experiential learning and created a support cohort to debrief about the progress weekly. The traditional faculty mentoring is predominantly in the style of students meeting with the designated faculty mentor and one on one unidirectional forward knowledge transfer [21].

Following the Kaul et al.’s [20] research suggestion, our findings support the possibility of their mentoring model $—$ a combination of peer-coaching, faculty mentor, and vertical integration mentor group. We extended the model by adding that what the internal mechanism from the P-E fit perspective. Student mentees may increase their self-efficacy based on the match between them and their mentors. Future studies should consider using quantitative methods to explore the effectiveness from the P-E fit perspective. A larger sample size is needed for future studies in order to increase the generalizability of the research results. From a design perspective, control group should be conducted in the future as see the effectiveness of P-E fit both qualitatively and quantitatively.

\section{Conclusion}

A better fit of mentors and mentees improve the relationship in mentoring. Mentees build a stronger bond with the mentors that help them the most. Future studies should consider attempting quantitatively measures on the strength between the mentor-mentee P-E fit and mentees' self-efficacy with a larger sample. 


\section{References}

1. Kanchewa, S.S., et al., Relational Experiences in School-Based Mentoring: The Mediating Role of Rejection Sensitivity. Youth \& Society, 2018. 50(8): p. 1078-1099.

2. Covington, M., T. Chavis, and A. Perry, A scholar-practitioner perspective to promoting minority success in STEM. Journal for Multicultural Education, 2017. 11(2): p. 149-159.

3. Haggard, D.L., et al., Who Is a Mentor? A Review of Evolving Definitions and Implications for Research. Journal of Management, 2011. 37(1): p. 280-304.

4. Evans, G.L. and K.O. Cokley, African American Women and the Academy: Using Career Mentoring to Increase Research Productivity. Training and Education in Professional Psychology, 2008. 2(1): p. 50-57.

5. Tran, K., G.T. Tran, and R. Fuller, West Yorkshire Mentor Scheme: teaching and development. Clinical Teacher, 2014. 11(1): p. 48-52.

6. Woods, C.S. and M. Preciado, Student-Mentor Relationships and Students' College Attitudes. Journal of Education for Students Placed at Risk, 2016. 21(2): p. 90-103.

7. Arthur, M.B., MENTORING AT WORK - DEVELOPMENTAL RELATIONSHIPS IN ORGANIZATIONAL LIFE - KRAM,KE. Administrative Science Quarterly, 1985. 30(3): p. 454456.

8. $\quad$ Rounds, J.B., \& Tracey, T. J., From trait-and factor to person-environment fit counseling: Theory and process. Career Counseling: Contemporary Topics in Vocational Psychology, 1990(1): p. 144.

9. Dennehy, T.C. and N. Dasgupta, Female peer mentors early in college increase women's positive academic experiences and retention in engineering. Proceedings of the National Academy of Sciences of the United States of America, 2017. 114(23): p. 5964-5969.

10. Raposa, E.B., et al., The Effects of Youth Mentoring Programs: A Meta-analysis of Outcome Studies. Journal of Youth and Adolescence, 2019. 48(3): p. 423-443.

11. Caprara, G.V., et al., Teachers' self-efficacy beliefs as determinants of job satisfaction and students' academic achievement: A study at the school level. Journal of School Psychology, 2006. 44(6): p. 473-490.

12. Schiefele, U. and E. Schaffner, Teacher interests, mastery goals, and self-efficacy as predictors of instructional practices and student motivation. Contemporary Educational Psychology, 2015. 42: p. 159-171.

13. Yoon, J.S., TEACHER CHARACTERISTICS AS PREDICTORS OF TEACHER-STUDENT RELATIONSHIPS: STRESS, NEGATIVE AFFECT, AND SELF-EFFICACY. Social Behavior \& Personality: an international journal, 2002. 30(5): p. 485-493.

14. Edwards, J.R., 4 Person-Environment Fit in Organizations: An Assessment of Theoretical Progress. Academy of Management Annals, 2008. 2(1): p. 167-230.

15. Kristof-Brown, A.L., R.D. Zimmerman, and E.C. Johnson, Consequences of individuals' fit at work: A meta-analysis of person-job, person-organization, person-group, and person-supervisor fit. Personnel Psychology, 2005. 58(2): p. 281-342.

16. Sandelowski, M., Telling Stories: Narrative Approaches in Qualitative Research. Image: the Journal of Nursing Scholarship, 1991. 23(3): p. 161-166.

17. Hesse-Biber, S., Qualitative Approaches to Mixed Methods Practice. Qualitative Inquiry, 2010. 16(6): p. 455-468.

18. Thomas, D.R., A general inductive approach for analyzing qualitative evaluation data. American Journal of Evaluation, 2006. 27(2): p. 237-246.

19. Shuman, M., et al. Work in Progress - Improving Self-Efficacy with a Freshman Mentor Program. in IEEE Frontiers in Education Conference 2008. 2008. Saratoga Springs, NY.

20. Kaul, S., et al., Triangulated mentorship of engineering students - leveraging peer mentoring and vertical integration. Global Journal of Engineering Education, 2019. 21(1): p. 14-23.

21. Ishiyama, J., Expectations and Perceptions of Undergraduate Research Mentoring: Comparing 
First Generation, Low Income white/Caucasian and African American Students. College Student Journal, 2007. 41(3): p. 540-549. 